Session 2451

\title{
A Modular Ammonia Stripping Tower Design Project for an Environmental Process Dynamics Course
}

\author{
Michael Keinath, Hildegarde Selig and Walter J. Weber, Jr. \\ Department of Civil and Environmental Engineering \\ University of Michigan, Ann Arbor
}

\begin{abstract}
As a requirement of a senior-level environmental process dynamics course, we developed a modular ammonia stripping tower design project. This course introduces fundamental principles of process dynamics in environmental systems, focusing on their modeling and design applications. The modular design project is intended to complement the "common sense approach" instructional philosophy of the class by adding complexity to the overall ammonia stripping tower design through successive modules. Each module corresponded to a topical section of the course with each successive module building on the work of the prior. This stepwise engineering application was designed in such fashion that by the end of the course the students completed a rigorous design of an ammonia stripping tower. To elicit a cooperative learning environment, all but the first of the modules were completed in self-selected groups of three to four students. The effectiveness of this instructional approach was assessed through student surveys before and after the project and analysis of student performance throughout the course. The initial survey revealed that students had a relatively high interest in taking the course despite thinking that it would be more difficult and have a heavier workload than the average UM engineering course. After completion of the project, students found the design modules to be productive and generally enjoyed doing them. The highest average rating (4.0/5.0) was attributed to enjoying working in a group. Overall, the modular design project was an effective way to promote the design process, elucidate relationships between fundamental processes and practical applications, balance students' workload throughout the semester and foster a cooperative learning environment.
\end{abstract}

\section{Introduction}

"Dynamics of Environmental Systems" is a senior-level course required for students focusing in environmental engineering and an elective for all other civil engineers. This course introduces the fundamental principles of process dynamics in environmental systems, focusing on their modeling and design applications. The typical enrollment is approximately 30 students with $25 \%$ as first-year graduate students. The course employed a "common sense approach" in which 
descriptions of processes and systems are introduced initially in their simplest intuitive forms, before rigorous mathematical description. Complexities are gradually added in a problemsolving manner, allowing students to gain an intuitive understanding of the fundamental principles involved. The interdependence between macroscale and microscale mass transport and transformation processes in environmental systems is emphasized throughout the course. Upon completion of the course the student should be able to: (i) identify and mathematically describe major processes occurring within different types of environmental systems, (ii) select system boundaries and process scales relevant to the level of analysis required, and (iii) characterize environmental systems in the form of rigorous mathematical models, that can be simplified and solved by selecting appropriate assumptions. The course is divided into six topical sections: system and process characterization and modeling; fluid flow and mass transport; diffusive mass transport and interface mass transfer; reaction equilibria and thermodynamics; interface reaction equilibria and thermodynamics; and kinetics and reaction rates in ideal reactors.

The goal of the modular design project is to complement the course by adding a design component without detracting from the traditional problem sets and exams of the course or overburdening the students with a dramatically increased workload. Our goal was to present the project in such a way that each module added complexity to the overall design in a stepwise manner, where each step corresponded to a topical section of the course. By closely linking the project modules with the processes covered in lectures, we hoped to show students the relationship between fundamental concepts and practical design considerations. A modular approach also serves to distribute the workload throughout the semester rather than a large endof-semester burden in which students can quickly lose interest and/or motivation.

\section{Components of Modular Design Project}

\subsection{Cooperative Learning}

With the exception of the first module that was completed individually, to promote cooperative learning, the four other modules were completed in student selected groups of 3-4 students. "Cooperative learning is the instructional use of small groups so that students work together to maximize their own and each other's learning." ${ }^{1}$ Research by the same authors has shown that students who participate in cooperative learning groups develop higher reasoning strategies and critical thinking skills than students who engage in the traditional competitive or individualistic

learning strategies. ${ }^{2}$ Through group work, we encouraged positive interdependence, however we also stressed individual accountability by having at least one question on each of the three exams directly relating to design modules. This forced each student to make a contribution to each module (personal accountability) and at the same time forced each student to made sure that their fellow group members understood all aspects of each module (positive interdependence).

\subsection{Choice of ammonia as target compound}

We chose ammonia as the target compound for primarily didactical reasons. Ammonia is considered a contaminant in many industrial and municipal systems, therefore a number of treatment technologies have been developed for ammonia removal. Subsequently, there is a large volume of reference material that is easily available for students to consult in completing the modules. An important factor in the selection of ammonia is its ability to be removed 
through air stripping. Though ammonia has a relatively low Henry's constant, as compared with volatile organic compounds such as TCE, ammonia can still be removed quite effectively through air stripping, especially at elevated temperatures. Finally, we chose ammonia over VOCs due to its interesting acid/base chemistry, since ammonia can only be removed through air stripping under high $\mathrm{pH}$ conditions. A high $\mathrm{pH}$ condition promotes high carbon dioxide fluxes into the ammonia-containing waste and carbonate chemistry is a major topic in environmental chemistry. Volatile organic compounds that are typically treated using air stripping do no have this $\mathrm{pH}$ dependence and though they are more aptly suited for removal through volatilization, we would have been unable to incorporate chemistry considerations into the design process as we were able to with ammonia.

\subsection{Choice of an air stripping tower}

Ammonia is a compound for which a number of treatment techniques have been shown to be effective for its removal. We chose to structure the design modules around an air stripping tower since that treatment technology, coupled with the chemical characteristics of ammonia, incorporates most of the topical aspects of the course into a singular unit operation. In designing an ammonia air stripping tower the students had to understand and use their knowledge of system and process characterization and modeling, fluid flow and mass transport, interface mass transfer, and reaction equilibria and thermodynamics. The overall basis for design of the counter-current packed-bed air stripping tower is presented in Section 10.3 of Process Dynamics in Environmental Systems ${ }^{3}$, a supplemental text for the course. This method for air stripper design presents the concepts of operating and equilibrium lines, the number of transfer units (NTU) and height of a transfer unit (HTU).

\subsection{Modules}

The overall project was composed of five modules, each corresponding to a different section of the course. Modules typically began with a page-long introduction/tutorial that provided most of the technical background required to complete the assignment. Student groups had 1-3 weeks to complete each module depending on its length and difficulty.

Module 1: Material Balance Approach. The first module was the problem set-up and was completed individually. In this module the basis of the problem was presented and students were asked to calculate mass removals and efficiencies based only on material balance relationships. This module corresponded well to the first section of the course, system and process characterization and modeling. Problems 1-5 and 1-6.

Module 2: Equilibrium Considerations. The second module added complexity to the design by considering thermodynamic considerations such as equilibrium, as described by Henry's law. This, and all subsequent modules, was completed in cooperative groups. Based on thermodynamic considerations, each group was asked to consider modes of packed-tower operation, both counter- and co-current. The groups were also asked to generate equilibrium and operating lines based on influent and target effluent concentrations. From this chart and corresponding equations, the groups made preliminary recommendations for operating parameters such as air flow rate. 
Module 3: Overall Stripping Tower Design. The third module was the longest and most conceptually difficult, yet it gave students insight into the practical requirements that must be considered in the design process. Once again this module added to the complexity of the design by addressing mass transfer and hydrodynamic considerations. To increase the Henry's constant of ammonia and increase the effectiveness of air stripping, we fixed the waste stream temperature at $90^{\circ} \mathrm{C}$. This forced the groups to consider temperature's effect on all other parameters, e.g. water density and viscosity. The design of the stripping tower was based on a minimum overall tower volume. Initially students were asked to construct a list of parameters and variables that they would need for the design. Students had to confront hydrodynamic constraints (e.g. tower flooding) through the use of the empirical Eckert relationship. ${ }^{5}$ For mass transfer consideration, the groups used the Onda mass transfer correlation to determine the overall mass transfer coefficient. ${ }^{6,7}$ Through this analysis, the groups were able to recommend the tower dimensions and operating parameters to meet the treatment objective.

Module 4: Chemistry Considerations. The fourth module capitalized on ammonia's interesting acid/base chemistry and asked the groups to consider how temperature and $\mathrm{pH}$ affect ammonia removal through air stripping. Due to the increased temperature, the groups had to look-up reaction enthalpies and recalculate equilibrium coefficients and then determine if ammonia could be removed under influent conditions. They then had to determine how to alter the influent so that ammonia could be removed and determine what effects their changes would have on operation of the stripping tower. Changes included $\mathrm{pH}$ adjustment with slaked lime $\left[\mathrm{Ca}(\mathrm{OH})_{2}\right]$. They were asked to determine the effect of an increase of carbonate in the system and evaluate the precipitation of $\mathrm{CaCO}_{3}$ and $\mathrm{CaOH}$ that causes scaling and other operational problems in these systems. They were also asked to consider how the stripping process changes the solution chemistry of the system.

Module 5: Wrap-Up. So that the students would get a feeling of the factors that most significantly affected their design, the final module asked the groups to complete a rudimentary sensitivity analysis. To give them a perspective of the overall design, we also required that they outline the steps in the design process and prepare a flowchart. Finally, to consider contingencies, we asked them to brainstorm possible system failures and adverse conditions that might cause the stripping tower to not meet its design removal efficiencies.

\subsection{Mentoring Support}

Since the material in the design modules was generally unfamiliar to students, we were careful to schedule additional office hours and recitations to accommodate students' questions. We also used three 2-hour recitation sections to present background material and hold in-class work sessions. Two of those sessions were conducted in a classroom computing facility so that groups could work on the design with direct access to an instructor. Additionally we scheduled meetings with individual groups if they were requested and answered questions via e-mail.

\subsection{Grading}

The overall grade for the modules was determined from two different components. The primary component $(90 \%)$ of the overall project grade was based on a group's performance on the modules, with the exception of the first module, which was completed individually. The 
remaining $10 \%$ of the grade was based on a measure of how well a group shared information amongst its members. A significant benefit of group work is to facilitate students sharing thoughts and ideas within their groups, developing a common solution and teaching each other along the way. One way to measure how well information is shared within a group is through an individual's performance on a test question based directly on the design modules. On each of the three exams, one question was dedicated to project material. We averaged those scores of each individual within a group to determine a composite score for each group. We assumed that groups with higher average composite scores were ones in which all members contributed to the modules and made sure that each member understood all aspects of each module. The final $10 \%$ of the overall project grade was then assigned based on this overall composite score of exam questions, with higher credit going to groups that exhibited a greater overall mastery of design principals.

\section{Assessment}

We assessed the effectiveness of these design modules through student surveys before and after the project and analysis of student performance in the course. At the beginning of the course, the students were asked to complete a brief survey polling their preconceptions of the course and project and to identify the types of courses they had previously taken. Initially students had a relatively high interest in taking the course despite thinking that the course would be more difficult and have a heavier workload than the average UM engineering course. When asked about the design aspect of the course, most students felt that it would enhance the class despite somewhat to significantly increasing the workload.

It is interesting to note trends in the students' overall course and design project performance. Based on exams and individual problem sets, there was a normal distribution of grades for overall course performance. As was expected for a group effort, performance was high throughout the class, even with those students that are otherwise below the class average. Interestingly, individual performance on project related exam questions has also been high, particularly among students that have not done as well in other aspects of the course. We feel that this results for the cooperative nature of the project where students maximize their own and each other's learning. In the cooperative project groups, students discuss concepts and help each other to identify and correcting each other's misconceptions, which was shown by their above average individual performance on project related exam questions.

After students completed all modules we conducted another anonymous survey to gauge their perceptions of the design modules. The survey consisted of eleven statements and an openended section for comments and suggestion. For the eleven statements, we asked the student to rate how well they agreed with each statement according to a five-point scale where a 1 indicated strong disagreement and 5 strong agreement. Numbers closer to five indicate a favorable response towards the project. Numerical results of the survey are presented in Table 1.

As is evident from the Table 1, the averages for all statements were between 3.3 and 4.0 with an average overall score of 3.7. This indicates that the students found the design modules to be productive and generally enjoyed doing them. It is interesting to note that the highest average rating (4.0) was attributed to enjoying working in a group. Another notably high mark (3.9) is associated with the expectation that the project would increase a student's grade in the course. 
This corresponds well with our observation that most students excelled at design project activities despite not doing so well in other aspects of the course. It is these students that we feel the design project is most benefiting. This once again reaffirms our expectation that cooperative learning maximizes each student's individual and a group's combined learning.

Table 1: Summary of students' responses to post-project survey. The table shows the number of students that responded to each category. The score indicates the numerical value placed on each response for averaging purposes.

\begin{tabular}{|c|c|c|c|c|c|c|c|}
\hline & $\begin{array}{l}\text { Strongly } \\
\text { Disagree }\end{array}$ & Disagree & $\begin{array}{c}\text { Somewhat } \\
\text { Agree }\end{array}$ & Agree & $\begin{array}{c}\text { Strongly } \\
\text { Agree }\end{array}$ & Omit & \\
\hline Score & 1 & 2 & 3 & 4 & 5 & 0 & Average \\
\hline The project increased my interest in the course material & & 3 & 11 & 7 & 1 & & 3.3 \\
\hline The project increased my understanding of course material & & 1 & 7 & 13 & 1 & & 3.6 \\
\hline The design project overall enhanced the class & & 2 & 7 & 11 & 1 & 1 & 3.5 \\
\hline The design project increased my grade in the course & & 1 & 6 & 8 & 5 & 2 & 3.9 \\
\hline The exercises of the design project were useful & & 1 & 7 & 12 & 2 & & 3.7 \\
\hline Overall I enjoyed working in a group & & 1 & 4 & 10 & 7 & & 4.0 \\
\hline The project increased my interest in the design process & & 2 & 8 & 9 & 3 & & 3.6 \\
\hline The project helped me to gain insight into the design process & & 1 & 4 & 15 & 2 & & 3.8 \\
\hline The material covered in the design project was interesting. & & 1 & 7 & 11 & 3 & & 3.7 \\
\hline \multirow[t]{2}{*}{ Overall I enjoyed doing the design modules. } & & 2 & 7 & 11 & 2 & & 3.6 \\
\hline & & & & & \multicolumn{2}{|c|}{ Overall Score } & 3.7 \\
\hline
\end{tabular}

In addition to the statements provided on the survey, a number of students provided comments and suggestions for improvement. One student commented the s/he "liked how the course project was broken up into these modules, it made having a course project less stressful at the end of the semester." Another student, however, commented that it would be better to have fewer modules that are "each longer as opposed to more modules that are shorter." In general most students felt that having the project split up into modules was beneficial and that the overall length of each module was fair (3.5/5.0).

On another topic a student commented that s/he "sometimes got lost in the details" and "an overall discuss[ion]/presentation of what we were designing, and why, would be helpful." It is very important to make sure the objectives and rationale of the project are well defined and effectively conveyed to the students. With respect to the correlation of the project and course material, one student wrote: "at times, the design project material seemed very much separate from the class material. However, the design project, I felt at times, was the only part of class attached to industry and what the work environment will be like. That I enjoyed." Though not always apparent, making connections between the fundamental processes presented in lectures and the practical considerations of the design process is very important. A design project like this one can be an ideal vehicle for making such connections.

\section{Conclusions}

We developed a modular design project of an air stripping tower for ammonia removal as part of an environmental process dynamics class. We placed a large emphasis on cooperative learning and required the modules to be completed in student-selected groups. Since the overall individual and group performance on project related material was quite high despite the conceptual difficulty of the material, we feel this cooperative approach greatly benefited the 
students' understanding and retention. The module format allowed us to closely structure each assignment with the corresponding topic areas in the course and distribute the workload throughout the semester. We were able to present the project in such a way that each module added complexity to the overall design in a stepwise manner and show students the relationship between fundamental concepts and practical design considerations.

\author{
References \\ ${ }^{1}$ Johnson, D.W., Johnson, R.T., and K.A. Smith. Active Learning: Cooperation in the College Classroom. Edina, \\ MN: Interactive Book Company. 1991, 1-25. \\ 2 Ibid., 5-7. \\ ${ }^{3}$ Weber, Jr., W.J. and F.A. DiGiano. Process Dynamics in Environmental Systems. New York: John Wiley \& Sons, \\ Inc. 1996, 719-726. \\ ${ }^{4}$ Ibid., 35. \\ ${ }^{5}$ LaGrega, M.D., Buckingham, P.L and J.C. Evans. Hazardous Waste Management. New York: McGraw-Hill Book \\ Company. 1994, 95-99, 447-460. \\ ${ }^{6}$ Onda, K. et. al. 1968. "Mass Transfer Coefficients Between Gas and Liquid Phases in Packed Columns," Journal \\ of Chemical Engineering of Japan, 1, 56-62. \\ ${ }^{7}$ Weber and DiGiano. 1996. 225-226.
}

\title{
MICHAEL KEINATH
}

Michael Keinath is a doctoral student at the University of Michigan, pursuing a combined Ph.D. in Environmental and Chemical Engineering. He received his B.S. in Chemical Engineering from Stanford University in 1996 and has earned M.S.E. degrees in Environmental Engineering and Chemical Engineering from the University of Michigan. Over the past two years Michael has been actively involved in the UM ASEE student chapter and is currently serving as President. His research interests include the development of green technologies for industrial waste treatment and pollution prevention.

\section{HILDEGARDE SELIG}

Hildegarde Selig is a postdoctoral research fellow and adjunct assistant professor in the Department of Civil and Environmental Engineering at the University of Michigan where she has taught both "Dynamics of Environmental Systems" and "Environmental Principles". She received her BS in Civil Engineering from Pedro Henriquez Ureña National University in Santo Domingo, Dominican Republic, her MS in Environmental Engineering from Michigan State University and her Ph.D. in Environmental Engineering from the University of Michigan. Her research interests include the mineral chemistry in aquatic systems and the coupling of phenolic compounds in natural soils and sediments.

WALTER J. WEBER, JR.

Walter J. Weber, Jr. is the Gordon M. Fair and Earnest Boyce Distinguished University Professor of Environmental Engineering and Science at the University of Michigan. He currently serves as the Director of the Institute for Environmental Sciences, Engineering and Technology which shapes, facilitates and coordinates environmental education and research activities throughout the UM College of Engineering. Dr. Weber is the author or co-author of three books and approximately 300 peer-reviewed technical publications. His research focuses on phase separation technologies and process and transport modeling in natural and engineered environmental systems, ranging from fundamental concept development through the modeling and design of full-scale systems. 